\title{
Questions of Theory and Practice: To Synthesis, Analysis and Evaluation Natural Systems of Pacific Russia Based on Models of Landscape Geosystems
}

\author{
V. T. Starozhilov \\ Pacific International Landscape Center, Far Eastern Federal University, Vladivostok, Russian Federation \\ Email: starozhilov.vt@dvfu.ru
}

How to cite this paper: Starozhilov, V. T. (2019). Questions of Theory and Practice: To Synthesis, Analysis and Evaluation Natural Systems of Pacific Russia Based on Models of Landscape Geosystems. Journal of Geoscience and Environment Protection, 7, 81-92.

https://doi.org/10.4236/gep.2019.71007

Received: November 22, 2018

Accepted: January 19, 2019

Published: January 22, 2019

Copyright $\odot 2019$ by author(s) and Scientific Research Publishing Inc. This work is licensed under the Creative Commons Attribution International License (CC BY 4.0).

http://creativecommons.org/licenses/by/4.0/

\begin{abstract}
The results of long-term author's scientific research in the field of geological and geographical study and landscape mapping of large regional links, such as Sikhote-Alinsky, Sakhalinsky, Kamchatsky, Anadyrsky, located in the Pacific landscape belt of Russia, are considered (Starozhilov, 2013). The studies were conducted at the medium scale $(1: 500,000)$ and were accompanied by landscape mapping (Starozhilov, 2016). The proposed article discusses the theory and practice of the overall results and the strategic vision of applying the landscape approach with selected examples. The wide range of possibilities of applying the landscape approach in studying the interaction of nature and society is emphasized. The importance and the indisputable need for the synthesis, analysis and assessment of natural systems based on the mapping of landscape geosystems to assess the environmental management of not only regional territories, but also of Pacific Russia as a whole are noted.
\end{abstract}

\section{Keywords}

Synthesis, Analysis, Assessment, Nature, Landscape Geosystems, Theory, Practice

\section{Introduction}

An essential feature of the modern stage is the expansion of the scope of applied landscape research. For decades, agriculture has been a traditional area of application of the principles and methods of landscape science. In the 1860s land- 
scape scientists began to participate in architectural planning. In the future, landscape-recreational studies will become especially popular (Starozhilov, 2013). Other applied areas include landscape engineering, landscape reclamation and others.

In general, based on the data obtained from applied research, an anthropogenic direction is formed, in which a person and the results of his activity are considered not only as an external factor disturbing the landscape, but also as an equal component of the system. One of the founders of the anthropogenic concept is given by Milkov F. N. (Milkov, 1973). The concept of the agrolandscape is given by Nikolaev V. A. (Nikolaev, 1987, 2003). Agrolandscape is an anthropogenic landscape, the natural vegetation of which in the vast majority of the territory is replaced by agrocenoses by fields, pastures, hayfields, and perennial crops. Geotechnical systems reviewed Reteyum A. M. (Reteyum, Dyakonov, \& Kunitsyn, 1972). The cultural landscape was discussed by Saushkin Yu. G. (Saushkin, 1946). A cultural landscape is an earthly space that is formed as a result of conscious, purposeful human activity to satisfy various practical needs, including all its natural and anthropogenic components.

Achievements of domestic and foreign geography are in studying the relationship and interaction of natural and anthropogenic factors, identifying sources, processes and consequences of anthropogenic environmental changes, features of regional combinations of environmental problems caused by economic and other factors. It is important that as a result a special general scientific method (or approach) was developed, the use of which has broad prospects. The essence of this approach is to analyze the observed phenomena and problems in connection with the landscape structure of the territory, human and natural environment (Sochava, 2005). An objective assessment of the role of the geographic environment in the life and development of society in combination with the landscape approach opens up new possibilities for explaining patterns in the economic development of the territory, using the complex of resources, creating environmentally safe development conditions, etc. The theoretical potential of landscape science as the core of physical geography, despite the presence of unresolved or controversial issues is of fundamental importance for the development of a general strategy of human behavior in its natural environment.

For applied research it is important that the landscape has a strict territorial physical and geographical position, it has local and regional properties that have qualitative and quantitative indicators. The landscape, expressed in natural boundaries, is the geographical basis for the organization of territories. Many specialists see their main applied task in identifying the landscape bases of the natural environment as a basis for the development of territories, and the author has been facing the same problem for many years. It is solved on the example of the possibilities of using the landscape approach to solving problems of diverse nature use and related environmental problems. Currently, regional specifics in the landscape geography of Russia are extremely limited in the number of works. Unfortunately, there is no such work in the vast region of Pacific Russia. With 
the existing absence of medium-scale landscape materials, including cartographic ones, leads to a violation of quality in choosing the best ways to develop production and conduct environmental protection measures; The lack of modern regional landscape-industrial cartographic materials in the assessment of anthropogenic transformations of the landscape environment negatively influences strategic decisions on the planning and development of the development of both individual regional and Pacific marginal continental landscape belts, in general, of Pacific Russia, and environmental protection measures. The interest in the development of natural resources of the region that has emerged in the present period, the planned intensive economic development and the associated increase in anthropogenic transformation makes the problem of synthesis, analysis and assessment of natural systems based on models of landscape geosystems extremely actual.

\section{Materials and Methods}

Article includes the results of many years of research author's work in the field of geological and geographical study and landscape mapping of major regional links such as Sikhote-Alinsky, Sakhalinsky, Kamchatsky, Anadyrsky, located in the Pacific landscape belt of Russia (Figure 1). They thematically continue landscape mapping and description of Russia, and medium-scale mapping (in particular Primorye) using regional-typological classification allowed to reflect the features of geosystems that manifest in different parts of their ranges, and the description revealed the properties and degree of differences between landscapes. Research in this area of physical and geographical science, aimed at developing landscape-ecological foundations environmental management strategies, is carried out in connection with the problem of the need to substantiate the optimization of geosystems in the context of economic activity and increased state attention to the development of Pacific Russia (Starozhilov, 2011).

Research is conducted at the medium-scale level of landscape research of continental territories and is accompanied by landscape mapping. For individual regional links (Primorsky krai), based on an in-depth component analysis, a landscape classification has been developed, a landscape map Primorsky Krai of 1:500,000 and a legend to it has been compiled. At the same time, spatial organization of landscapes was studied based on the use of statistical methods of areal quantitative and qualitative distribution of landscapes, species and other units. The areas, the quantitative ratio of the classification units of landscapes are calculated (Starozhilov, 2013). For the first time, features of the formation of the basement of landscapes were revealed according to the results of a study of the petrographic composition of rocks and the structural and tectonic position of sedimentary and other complexes (on the example of Sikhote-Alin, Sakhalin, Hokkaido, Kamchatka geosystems) are shown (Starozhilov, 2004). The features of the structure and organization of landscapes are revealed. The analysis of the system of natural landscapes with the reflection of their spatial-spatial horizontal and altitudinal differentiation is carried out. An assessment of the 


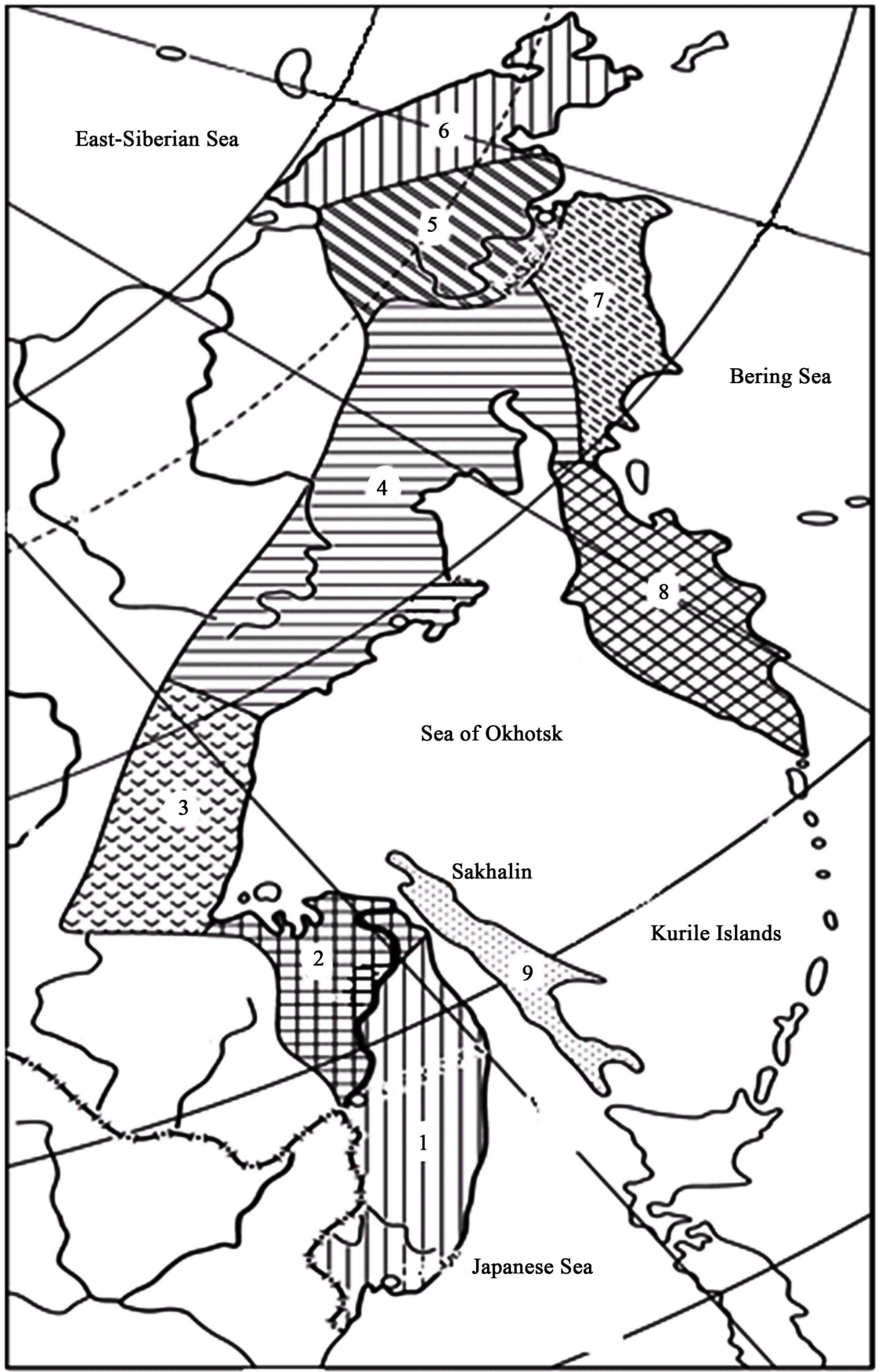

Figure 1. Pacific landscape belt of Russia. Belt areas: 1. Sikhote-Alinskaya, 2. Low-Amurskaya, 3. Priokhotskaya, 4. Kolymskaya, 5. Anadyrskaya, 6. Chukotskaya, 7. Koryakskaya, 8. Kamchatskaya, 9. Sakhalinskaya.

spatial distribution of landscapes and their quantitative parameters is given. On the whole, the landscape geosystem of Primorye is modeled. A landscape approach is presented for an integrated analysis of anthropogenic transformations while ensuring the environmental safety of mineral and other types of environmental management. According to the developed method of medium-scale mapping, the in-depth component analysis and landscape mapping of Sakhalin 
(Starozhilov, 2011), Kamchatka and other regional territories of the continental-continental landscape belt of Pacific Russia continues. Based on the marked cartographic materials of medium scale by region, as well as landscape maps of the Union of Soviet Socialist Republics, edited by E. A Goodilin, A.G. Isachenko and others, the synthesis, analysis and assessment of applied aspects of natural systems was carried out.

The method of landscape anology (indication) is applied. The essence of the method lies primarily in the dissemination of knowledge about a part of an object or its structural element over the entire nature management object. A comparative analysis of the studied (basic) and unexplored territories is carried out. It allows you to compare the studied territories with unexplored objects and to predict the unknown structure, properties and unknown effectiveness of a new unexplored area of research on the past results of existing studies. The application of the method allows using anology with examples of medium-scale studies of individual regional territories (Primorskaya, Sakhalinskaya and others). To gain knowledge about the features and internal content of environmental management, as well as carry out synthesis, analysis and evaluation. Natural systems based on the modeling of landscape geosystems of a larger geographic space.

\section{Results}

Until recently, there were no necessary digitized landscape maps and simulated with the allocation of localities, species, genera, subclasses, classes, landscape types, landscape districts, provinces and regions of landscape geosystems models of regional links in Pacific Russia, including Primorsky level. This means that there were no conditions for a comprehensive multi-purpose assessment of the possibilities of using the landscape approach. Therefore, with the advent of landscape maps of 1:500,000 scale, zoning maps of 1:1,000,000 scale and, in particular, the model of the landscape geosystem of Primorye, it was possible using the above presented and published materials to assess the possibilities of using the landscape approach as a basis:

1) Comprehensive assessment of the status of environmental objects in the landscape system of the region.

2) Comprehensive regional assessment of environmental problems.

3) On the issue of integrated assessment of technogenic transformations of landscapes in environmental management.

4) Regional search for mineral resources.

5) Comprehensive assessment of land management of agricultural enterprises.

6) Landscape conditions for the development of erosion-denudation processes in the south of the Far East.

7) Characteristics of soil properties in landscape flood zones with flood waters.

8) Denudation processes in landscapes and geoecological prerequisites of man-made changes. 
9) Geoecology of landscapes of a zone of influence of a thermal power station.

10) Geoecology of the mineral resource use of landscapes in the South of the Far East.

11) The processes of mechanical soil degradation in landscapes of Primorye (Starozhilov, 2013).

12) Features of chemical soil degradation in landscapes of the south of the Far East.

Below, the theory and practice of general results and the strategic vision of applying the landscape approach are considered only by the example of solving individual tasks (in the article it is simply not possible to consider, by the example of all the above tasks): 1) Comprehensive assessment of the status of environmental objects in the landscape system of the region; 2) Comprehensive regional assessment of environmental problems; 3) On the issue of integrated assessment of technogenic transformations of landscapes in environmental management.

1) Comprehensive assessment of the status of nature management objects in the system of landscapes in the region. At the same time, under the landscape status, understanding the landscape-component specificity of the territories of development objects that experience technogenic transformations in the space of different-rank dynamic geosystems. The study of the landscape state of development objects was carried out using the example of industrial coal and mining centers of Primorye. It is established that they occupy a certain place, both in the hierarchy of natural landscapes, and in the geographical space of regions, provinces and regions (Figure 2). As a result of studying the landscape structure and location of the coal-ore centers of Primorsky Krai, a certain landscape location of production facilities was established in all hierarchical units of the Primorye landscape geosystem model: areas, types, genera, subclasses, classes, counties, provinces and regions (Table 1). It became possible to make such a landscape reference and landscape characteristic only on the basis of a medium-scale landscape map and a regionalization map that appeared in Primorye. In addition, the emergence of such digitized maps has identified the possibility of using them in determining the landscape status and landscape description of any objects studied, which will increase the quality and strengthen the authentic significance of the tasks being solved in the study and development of territories.

2) Comprehensive regional assessment of environmental problems. Great importance is attached to research on the ecological assessment of landscapes. This is due to the fact that it is on their properties and state that such important for a person and at the same time vulnerable functions of anthropogenic influences as environmental protection and resource reproduction depend (Kochurov, 1997).

It is known that these landscapes are fully capable of performing landscapes that are in an undisturbed state or controlled by man. If the natural components are violated, the performance of these functions becomes incomplete or completely stops. This naturally leads to damage and greatly affects the degree of 


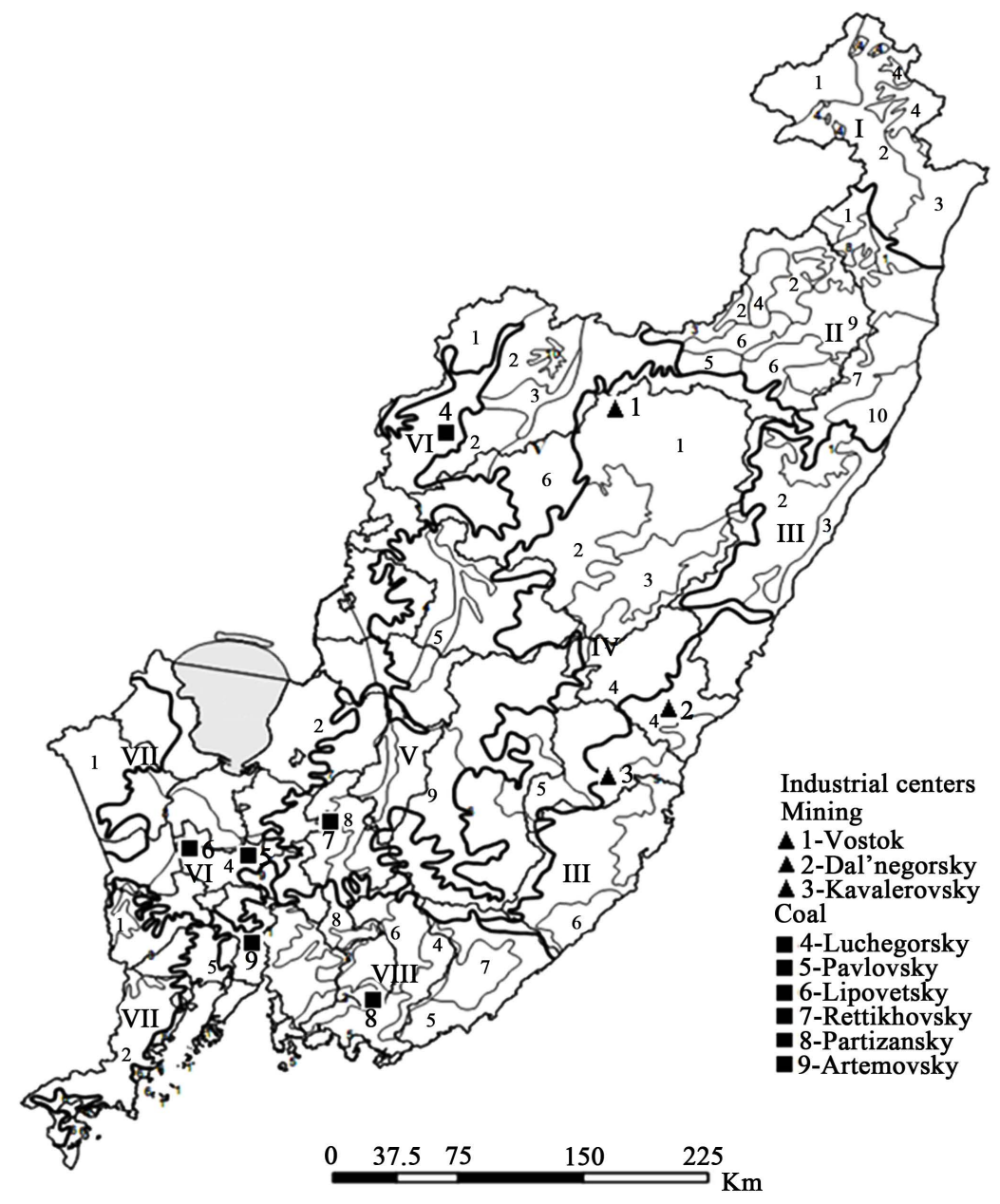

Figure 2. Map of physiographic zoning and the position of some industrial coal and mining centers of mineral raw materials production. Sikhote-Alinskayaphysico-geo-graphical area: I Samorginskaya Physico-geographical province: 1. Verkhne-Samor-ginskaya, 2. Sredne-Samorginskaya, 3. Nizko-Samorginskaya, 4. Issimovskoe plato; II North Sikhote-Alin Physico-geographical province: 1. Verkhne-Yedinskiy, 2. Verkhne-Bikinskiy, 3. Verkhne-Katenskiy, 4. Klyuchevoy, 5. Rodnikovyy, 6. Svetlovodnyy, 7. Kuznetsovskiy, 8. Yedinskogo plato, 9. Zavinskogo plato, 10. Maksimovskogo plato; III East Sikhote-Alin Physico-geographical province: 1. Verkhne-Maksimovskiy, 2. Kemskiy, 3. Pribrezhno-Terneyskiy, 4. Margaritovsko-Rudnevskiy, 5. Olginskiy, 6. Margaritovskiy; IV Central Sikhote-Alin Physico-geographical province: 1. Arminskiy, 2. Perevalnenskiy, 3. Kolumbiyskiy, 4. Verkhneussursko-Verkhnekamskiy, 5. Verkhnepavlovskiy, 7. Prizhval'sko-Izvilistyy; V West Sikhote-Alin Physico-geographical province: 1. Alchinskiy, 2. Nizhne-Bikinskiy, 3. Bikinskiy, 4. Vodorazdel'nyy, 5. Malinovskiy, 6. Samarsko-Rosh-chinskiy, 7. Sinegorskiy, 8. Arsenyevskiy, 9. Arsenyevsko-verkhneussurskiy, 10. Bikinskogo plato. Ussuri-Khankaya physico-geographical area: Physico-geographical province: VI Zapadno-Primorskaya plain Physico-geographic districts: 1. Sredneussuriskiy, 2. Prikhankayskiy, 3. Voznesenskiy, 4. Sredne-Razdolnenskiy, 5. Razdolnenskiy, 6. Pribrezhnyy. East-Manzhurskaya physico-geographical area: Physico-geographical province: VII East-Manzhurskaya Physico-geographic districts: 1. Pogranichnyy, 2. Khasanskiy, 3. Borisovskoye plato. South-Primorskaya physico-geographical Area: Physico-geographical province: VIII South Primorskaya Physico-geographic districts: 1. Muravyev-Amurskiy, 2. Tumanskiy, 3. Livadiyskiy, 4. Partizanskiy, 5. Partizansko-Kiyevskiy, 6. Verkhne-Partizanskiy, 7. Benevskiy, 8. Shkotovskoye plato, 9. Ilistogo plato. 
Table 1. Landscape position of coal and mining centers, deposits Primorsky Krai (fragment).

\begin{tabular}{|c|c|c|c|c|c|c|}
\hline Region & Provinces & District & Class & Subclass & $\begin{array}{c}\text { Rod } \\
\text { (prevails) }\end{array}$ & $\begin{array}{l}\text { Industrial } \\
\text { centre, } \\
\text { minefield }\end{array}$ \\
\hline \multirow{3}{*}{ Sikhote-Alinskaya } & & Margaritovsky-Rudny & Mountain & $\begin{array}{l}\text { Mountain forest } \\
\text { mixed broadleaf }\end{array}$ & $\begin{array}{l}\text { Dismembered } \\
\text { polysubstrate }\end{array}$ & Dalnegorsky \\
\hline & $\begin{array}{c}\text { Central } \\
\text { Sikhote-Alinskaya }\end{array}$ & Arminsky & Mountain & $\begin{array}{l}\text { Mining } \\
\text { dark coniferous }\end{array}$ & $\begin{array}{c}\text { Massively-dismembered } \\
\text { srednegorny polisubstratnye }\end{array}$ & Vostok \\
\hline & $\begin{array}{c}\text { East } \\
\text { Sikhote-Alinskaya }\end{array}$ & $\begin{array}{l}\text { Verkhneussursko- } \\
\text { Verkhnekemsky }\end{array}$ & Mountain & $\begin{array}{l}\text { Mountain dark } \\
\text { coniferous } \\
\text { mountain forest } \\
\text { mixed broadleaf }\end{array}$ & $\begin{array}{l}\text { Massively-dismembered } \\
\text { srednegorny polisubstratnye }\end{array}$ & Kavalerovsky \\
\hline \multirow[b]{2}{*}{ Ussuri-Khankaskaya } & \multirow[b]{2}{*}{ Ussuri-Khankaskaya } & Middle-Ussursky & Flat & $\begin{array}{c}\text { Forest-steppe } \\
\text { plain and } \\
\text { valley-river }\end{array}$ & $\begin{array}{l}\text { Erosion-accumulative } \\
\text { plain and valley river }\end{array}$ & Luchegorsky \\
\hline & & Middle-Razdolnensky & Flat & $\begin{array}{c}\text { Forest-steppe } \\
\text { plain and } \\
\text { valley river }\end{array}$ & $\begin{array}{l}\text { Erosion-accumulative } \\
\text { plain and valley river }\end{array}$ & Pavlovsky \\
\hline \multirow{2}{*}{ South Primorskaya } & \multirow{2}{*}{ South Primorskaya } & Muravyev-Amurskiy & Mountain & $\begin{array}{l}\text { Mountain forest } \\
\text { broadleaf }\end{array}$ & Lowland terrigenous & Artyomovsky \\
\hline & & Upper-Partizanskiy & Mountain & $\begin{array}{l}\text { Mountain-forest } \\
\text { mixed broadleaf }\end{array}$ & Lowland terrigenous & Partizanskiy \\
\hline
\end{tabular}

satisfaction of human needs. This means that all the properties and state of the natural environment, indicating the degree of its well-being (distress), are environmentally significant for humans.

In assessing environmental problems, first of all, applied the method of landscape indication. It includes the study of indicators and indicator links reflecting the objects of indication caused by anthropogenic transformation, the development of measures to protect the natural environment (Bulatov \& Vinokurov, 1989; Starozhilov, 2013). At the same time, an important stage of the work was the analysis of the established system of territory use, showing the spatial organization of landscapes and the use of comparative areal characteristics of natural and modified landscapes.

To obtain data on the areas and properties of the natural landscapes of the region, it is necessary to have a digitized landscape map. Such a map was compiled, the areas of the landscapes identified on it were calculated. These data were used to calculate the ratio of areas of indicators of modified and natural landscapes. Their identification and analysis is important in determining the degree of transformation of landscapes and in determining landscape-ecological consequences and environmental protection measures. But not all indicative components can be represented in quantitative, countable form. Elements such as changes in the chemical composition of waters, soils, volumes of recoverable raw materials, rocks, reduction of biomass, reduction of land, land resources, destruction of unique natural tracts, protected species of fauna and flora are relatively easily determined. It is much more difficult to determine the phenomena 
and processes that arise as a secondary consequence of man-made factors, the chain of transformation.

Indicative components of any analyzed systems are spread over a certain area and taking into account the ratio of the areas of natural and modified landscapes in analyzing the transformation of mining areas is indicative of determining the degree of their modification. When analyzing the landscape approach for the purpose of studying the degree of transformation of landscapes by indicator components, we also studied the degree of indication from the ratio of areas of indicators of natural and modified systems. The ratios of the areas of soil, relief, geochemical, and other indicator components were determined; they are designated by coefficients.

There are a number of factors: $K_{1}, K_{2}, K_{3}$, etc.

$K_{1}, K_{2}, K_{3}, K_{n}$-coefficients of ratios of the areas of landscape natural (reference) and technogenic indicator components of landscapes (soil, plant, geochemical, etc.). The coefficients were calculated using the formula:

$$
K=P L / C L
$$

where:

$K$-area ratio of the corresponding component indicator of the landscape;

$P L$ - the area of the natural (reference) landscape;

$C L$-the area of the modified corresponding component indicator of the landscape;

The calculation of the component (for example, destroyed soil, a natural indicator of the landscape) changes in the landscape was made on the example of Rettikhovsky coal mine, which occupies $4.9 \mathrm{sq} \cdot \mathrm{km}$. It is located in a low-mountain forest-leaved forest with growths of thickets on aleurolite-sandstone complex of an area with an area of 34.1 sq.km (Table 2). Applying the above formula, we obtain the value of the coefficient of change of the component soil indicator of the area. It is equal to 6.8 .

Such data were obtained not only from Pavlovsky and Rettikhovsky coal mines, but also from Luchegorsky and Lipovetsky (Table 2), etc.

Analyzing the data of the ratio of indicators of landscapes and areal disturbance of natural areas on Luchegorsky, Pavlovsky, Lipovetsky, Rettihovsky (Table 2), we can state that in general the exploitation of the marked coal mines occurs under conditions of strong $(K-3.2 ; 6.8)$ and medium $(K-11.2 ; 11.4)$ environmental changes of localities.

Table 2. The ratio of the area of natural and modified landscapes (fragment).

\begin{tabular}{cccc}
\hline $\begin{array}{c}\text { Industrial } \\
\text { Center }\end{array}$ & $\begin{array}{c}\text { Area } \\
\text { Modified landscape sq.km }\end{array}$ & $\begin{array}{c}\text { Area, } \\
\text { sq. km of natural landscape }\end{array}$ & $\begin{array}{c}\text { Area } \\
\text { ratio }\end{array}$ \\
\hline Luchegorsky & 61.2 & 193.6 & 3.2 \\
Pavlovsky & 50.2 & 561.4 & 11.2 \\
Lipovetsky & 30.8 & 343.3 & 11.4 \\
Rettihovsky & 4.9 & 34.1 & 6.8 \\
\hline
\end{tabular}


According to the data obtained, three degrees of change in natural properties are highlighted: strong (for example, changes in the natural properties of the landscape with coefficients less than 10), medium (coefficients are in the range from 10 to 50), and weak (excess coefficients are more than 50). In real conditions, this is expressed in the destruction of many facies and tracts (undulating plains, gently sloping polysubstratum, accumulative valley-river, etc.) replacing them with man-made (dumps, tiled, etc.).

Analysis of landscape materials in the Primorsky Territory (as an example) and the obtained data on the coefficients and areal changes in the properties of the natural-territorial complexes allows you to identify the main types of landscape changes: natural resource, dynamic, landscape-genetic. Natural resources associated with the depletion and loss of natural resources and the deterioration of economic activity in the territory. Landscape-genetic due to the violation of the integrity of the landscape. Dynamic show the direction of technological transformation and changes in the evolutionary development.

As a whole, based on the results of these examples of the analysis of the territory and properties of landscapes, we note that the assessment of environmental problems depends on the availability of mythological landscape maps and knowledge of the geographical structure of the territories. Their use more effectively and objectively will allow to assess the degree of severity of environmental problems and the scale of landscape changes due to a more reasonable and clear definition of the boundaries of landscape-ecological transformations.

3) On the issue of integrated assessment of technogenic transformations of landscapes in environmental management. When analyzing the possibilities of the landscape method, as a basis for a comprehensive assessment of anthropogenic transformations of landscapes in areas of nature management, the method of landscape indication was applied. It includes the study of indicators and indicator links reflecting the objects of indication caused by anthropogenic transformation, the development of measures to protect the natural environment (Bulatov \& Vinokurov, 1989). In the process of landscape research of the territory, along with local indicators-soils, vegetation, relief, geology, climate-integral is also important-the specificity of the morphological structure. It shows the interrelation of elements and components of landscapes. The morphological structure formed by the complex interaction of endogenous and exogenous factors is an objective reflection of the complex processes of material-energy exchange between the components, so the analysis of its spatial order in systems of any rank appears as an important feature indicative of the natural process. The essence of the method of morphological landscape indication in its application to the knowledge of interrelated objects of nature, the economy consists primarily in the dissemination of knowledge about a part of an object, or its structural element, to the entire object of nature management. The method of landscape indication allows to solve not only the issues of transformation of individual components of landscapes, but also expand the limits of applicability of the method and expand it to the following scientific and educational processes: 
1) Landscape-indicative interpretation of all the information obtained on landscape modification and nature protection, taking into account the identified structural and functional similarity of geosystems, their typological similarity;

2) Creation of sectoral thematic maps on a single landscape basis, design of their interconnected and spatially comparable series;

3) Development on the basis of landscape-indicative concept of a rational scheme of environmental management of the entire system of project documents;

4) Implementation of a search for causal relationships, including direct, indirect, indirect (water quality, geochemical features of the object, etc.) based on the landscape indication.

Under the conditions of the growing role of the environmental factor, landscape indication acts as the basis for choosing the main direction or even a management strategy.

Performed, taking into account these ideas, practical studies have led to the conclusion that there are landscape indicators of anthropogenic transformation and modification, the stability of geosystems, the impact on the environment. The indication meaning of load thresholds, geographically-differentiated standards for maximum permissible concentration, change factors, impacts, and resources of reproducing functions deserves attention. Indicative assessment of such phenomena, properties and characteristics greatly facilitates the search and determines the geographical differentiation of measures for the protection and reproduction of natural resources.

It is revealed that for the evaluation of anthropogenic impacts on natural systems in the formation of nature-using (for example, mining) production, and associated adverse processes and phenomena, it is advisable to use two approaches: geosystem and component-wise. Analyzed, in particular, changes in lithology and topography, groundwater and surface water, atmosphere and microclimate, soil cover and vegetation. The accumulated information in landscape analysis, as a scientific basis of anthropogenic changes in the geosystem approach, allows within the ranges (areas) of landscapes:

1) Identify the main types, scale and nature, trends in natural systems and individual components;

2) To establish links between changes in nature and their effects, taking into account chain reactions in natural systems;

3) Conduct zoning on the nature and extent of changes in nature, to identify areas with its critical state;

4) Determine the degree of transformation of nature according to environmental criteria.

Differences in nature, activity and intensity of impact on natural landscapes in combination with nature conservation approaches provide the basis for the formation of the nature management concept of production, the development of standards, gradations of environmental quality after the inclusion of numerous systematic data on the types of components in the assessment. 


\section{Conclusion}

Finishing the presentation of the concept of a general assessment of the possibilities of applying a landscape approach in solving environmental problems, within the framework of landscape geography, using the example of Primorye, Sakhalin and others, we note the importance and the indisputable need to synthesize, analyze and evaluate natural systems based on the mapped landscape geosystems of Pacific Russia. To do this, it is necessary to continue the mapping of landscapes and make a medium-scale landscape map of Pacific Russia. Only in the presence of cartographic modern medium-scale materials on this territory is possible a significant synthesis, analysis and assessment of the environmental problems of landscape geosystems.

\section{Conflicts of Interest}

The author declares no conflicts of interest regarding the publication of this paper.

\section{References}

Bulatov, V. I., \& Vinokurov, Y. I. (1989). Landscape Indication in the Solution of Problems of Environmental Management. Landscape Indication for Rational Use of Natural Resources (pp. 12-19). MFGO.

Kochurov, B. I. (1997). Geography of Environmental Situations (Eco-Diagnostics of Territories) (pp. 132).

Milkov, F. N. (1973). Man and Landscapes. Science, 224.

Nikolaev, V. A. (1987). The Concept of Agricultural Landscape, West (Ser. 5, № 2, pp. 22-27). Moscow: Moscow State University.

Nikolaev, V. A. (2003). Landscape Science: Aesthetics and Design (pp. 176). Aspect Press.

Reteyum, A. M., Dyakonov, K. N., \& Kunitsyn, L. F. (1972). Interaction of Technology with Nature and Geotechnical Systems (Ser. Geogr., № 4, pp. 46-55). Izv. Academy of Sciences of the USSR.

Saushkin, Y. G. (1946). Cultural Landscape. Vopr. Geography, 1, 97-106.

Sochava, V. B. (2005). Selected Works. Theoretical and Applied Geography (pp. 288). Novosibirsk: Science.

Starozhilov, V. T. (2004). Geodynamic Evolution of the Transition Zone of Northeast Asia to the Pacific Plate. In the Collection: Hydrometeorological and Geographical Research at the Far Eastern Scientific Conference (pp. 85-87).

Starozhilov, V. T. (2011). General Landscape Science and the Use of Landscape Approach in Environmental Monitoring of Environmental Management. Lectures (pp.297). Vladivostok: Ministry of Education and Science of the Russian Federation, Federal Agency for Education, Far Eastern Federal University.

Starozhilov, V. T. (2013). Landscape Geography of Primorye (Regional Component Specificity and Spatial Analysis of Geosystems): Monograph/V.T. Starozhilov; [Scientific ed. I.A. Bulatov] (pp. 276). Vladivostok: Publishing House Dalnevost, Federal Union.

Starozhilov, V. T. (2016). Landscape Geosystems of the Sakhalin Region of the Pacific Region. Problems of Regional Ecology, No. 5, 53-57. 